\title{
Expression of accessory molecules and cytokines in acute EAE in marmoset monkeys (Callithrix jacchus)
}

\author{
Jon D. Laman a,b,*,1, Marjan van Meurs ${ }^{\text {a }}$, Marc M. Schellekens a ${ }^{a}$, Mark de Boer ${ }^{\mathrm{c}}$, \\ Bert Melchers ${ }^{\text {d, Luca Massacesi }}{ }^{\text {e }}$, Hans Lassmann ${ }^{\text {f }}$, \\ Eric Claassen ${ }^{\mathrm{b}}$, Bert A. 't Hart ${ }^{\mathrm{g}}$ \\ ${ }^{a}$ Division of Immunological and Infectious Diseases, TNO Prevention and Health (TNO-PG), PO Box 2215, 2301 CE Leiden, The Netherlands \\ ${ }^{\mathrm{b}}$ Department of Immunology, Erasmus University, Rotterdam, The Netherlands \\ ${ }^{c}$ PanGenetics BV, Amsterdam, The Netherlands \\ ${ }^{\mathrm{d}}$ Department of Pharmacology, TNO Defense Research (TNO-DO), Rijswijk, The Netherlands \\ ${ }^{\mathrm{e}}$ Department of Neurological Science and Psychiatry, University of Florence, Florence, Italy \\ ${ }_{\mathrm{f}}^{\mathrm{f}}$ Institute of Neurology, University of Vienna, Vienna, Austria \\ ${ }^{\mathrm{g}}$ Department of Immunobiology, Biomedical Primate Research Centre (BPRC), Rijswijk, The Netherlands
}

Received 5 September 1997; revised 23 December 1997; accepted 23 December 1997

\begin{abstract}
Accessory molecules and cytokines are involved in the immunopathogenesis of multiple sclerosis (MS) and experimental autoimmune encephalomyelitis (EAE) in rodent models, and are potential targets for immunotherapy. Evaluation of such experimental therapies requires appropriate animal models. Therefore, we analysed the expression of selected accessory molecules and cytokines in the brain of marmoset monkeys (Callithrix jacchus) with acute EAE, a newly described non-human primate model for MS. All animals experienced active disease clinically and histopathologically with strong resemblance to MS. Perivascular infiltrates of mononuclear cells showed abundant expression of CD40. CD40 was expressed on macrophages, indicating that $\mathrm{T}$ cell priming and macrophage effector functions may result from local CD40-CD40L interactions. CD40 ligand (CD40L) and B7-2 (CD86) were also expressed, but to a lower extent, while B7-1 (CD80) expression was limited. Both pro-inflammatory and anti-inflammatory cytokines were produced within individual lesions during active disease (IFN- $\alpha$, IFN- $\gamma$, TNF- $\alpha$, IL-1 $\alpha$, IL-1 $\beta$, IL-2, IL-4, IL-10 and IL-12). This suggests that relative levels rather than sequential expression of Th1- and Th2-type cytokines determine disease activity. These findings demonstrate the value of EAE in marmoset monkeys as a model to assess the role of accessory molecules and cytokines in multiple sclerosis, and to evaluate targeted intervention. (C) 1998 Elsevier Science B.V. All rights reserved.
\end{abstract}

Keywords: Multiple sclerosis; CD40; CD80; CD86; Macrophages; Non-human primates

\section{Introduction}

Multiple sclerosis (MS) is a chronic progressive disease affecting the white matter of the central nervous system

\footnotetext{
Abbreviations: CD40L-CD40 ligand; CNS, central nervous system; EAE, experimental autoimmune encephalomyelitis; MAb, monoclonal antibody; MRI, magnetic resonance imaging; MS, multiple sclerosis

* Corresponding author. Tel.: + 3171 5181542; fax: +31 71 5181901; e-mail: jd.laman@pg.tno.nl

${ }^{1}$ Tel.: +31 10 4087796; fax: +31 10 4367601; e-mail: laman@immu.fgg.eur.nl
}

(CNS), characterized by neurological dysfunction due to inflammatory lesions and breakdown of the myelin sheath which isolates axons. Initially, axons themselves are spared, but in advanced MS irreversible axonal loss contributes to neurological symptoms. Mononuclear cell infiltrates are composed of T cells, monocytes /macrophages and B cells. Local interactions between these cell types and brain glia cells are mediated by accessory molecules and cytokines. This interplay is thought to trigger effector mechanisms contributing to inflammation and myelin breakdown (reviewed by Lassmann, in press).

Classically, MS has been studied by means of EAE models in rats and mice (Lassmann, 1983; Swanborg, 
1995). In these models, animals are immunized with CNS homogenate or components derived thereof (e.g., myelin basic protein, proteolipid protein, or peptides) mixed in strong adjuvants, typically Freund's complete adjuvant. Subsequently, animals develop clinical signs of disease, including weight loss and progressively ascending paralysis. Rodent models include monophasic and chronic relapsing patterns of disease, allowing study of both the active (relapses, exacerbations) and remission phases of the disease. Extensive experimental evidence indicates that EAE results from the synergy between myelin-reactive $T$ cells and antibodies. Inflammation is likely primarily mediated by T cells (Swanborg, 1995), but for demyelination the involvement of opsonizing antibodies and complement appears essential (Linington and Lassmann, 1987; Linington et al., 1992; Genain et al., 1995). T cell autoreactivity may be provoked by major and minor myelin constituents like myelin basic protein, proteolipid protein and myelin oligodendrocyte protein. In addition, non-myelin proteins like S-100 $\beta$ (Kojima et al., 1993), the heat-shock protein alpha-B crystallin (Van Noort et al., 1995), and functional molecular mimicry between infectious agents and myelin constituents may be involved (Wucherpfennig and Strominger, 1995).

In MS and EAE, antigen-specific and non-specific interactions between CNS-infiltrating mononuclear cells and interactions of these cells with brain glia cells are mediated by accessory molecules and cytokines. A wide range of cytokines is involved in the different stages of the disease (Liles and Van Voorhis, 1995; Olsson, 1995; Woodroofe, 1995). Several groups have shown that costimulatory molecules B7-1 (CD80) and B7-2 (CD86) play a role in the disease (Cross et al., 1995; Khoury et al., 1995; Kuchroo et al., 1995; Miller et al., 1995; Perrin et al., 1995; Racke et al., 1995; Arima et al., 1996). We have recently demonstrated that $\mathrm{CD} 40-\mathrm{CD} 40 \mathrm{~L}$ interactions are crucial in EAE in SJL-mice induced by a peptide of proteolipid protein $\left(\mathrm{PLP}_{139-151}\right)$ (Gerritse et al., 1996). This observation was subsequently confirmed in CD40L deficient mice (Grewal et al., 1996). In addition, CD40 is abundantly expressed within the brain of MS patients, mostly by cells of the monocytic lineage, and therefore we proposed that CD40-CD40L interactions form a target for therapy in exacerbations of MS (Gerritse et al., 1996).

Similarities in the expression of accessory molecules and cytokine profiles in the CNS have been found between rodent EAE models and human MS (Olsson, 1995; Swanborg, 1995). However, important differences also exist, especially in the pathology of the lesions (Lassmann, in press), hampering elucidation of MS immunopathogenesis based on rodent studies. Data from our own laboratories (manuscript in preparation) and from other groups indicate that the new EAE model in marmoset monkeys (Callithrix jacchus) closely resembles MS with respect to clinical presentation, white matter lesion formation in vivo as assessed by magnetic resonance imaging (MRI), and CNS histopathology (Genain et al., 1994; McFarland, 1994; Genain et al., 1995; Massacesi et al., 1995; Genain et al., 1996).

The marmoset EAE model offers several features that can complement, but not replace, studies in rodents. Common marmosets $(C$. jacchus) are small New World monkeys. Adult marmosets weigh about 300-400 g, and are relatively simple and cheap to maintain and handle for experimental purposes. Marmosets are usually born as twins with a natural bone marrow chimerism. Hence, adoptive transfer studies can be done between genetically distinct siblings. In contrast to the inbred strains used in rodent models, marmosets are outbred, and as such better mimick the situation in the human population. Despite their outbred nature, a high EAE disease incidence of up to 100\% can be reached (e.g., Massacesi et al., 1995, and this study). Because of the close evolutionary relationship between marmosets and humans, also on the level of immunological cross-reactivity, the marmoset EAE model can be used for efficacy testing of new therapies with human-specific biological molecules, such as cytokines and antibody-based constructs. The species-specificity of many of these molecules makes most rodent models less valid for evaluation. Marmosets are also excellently suited for non-invasive imaging of lesion formation within the CNS by means of MRI, which is an increasingly important diagnostic method in MS. This allows in vivo studies followed by detailed immunopathological analysis of MRI-detectable lesions (manuscript in preparation). EAE induced in marmosets by protocols resembling those used for rodents (Massacesi et al., 1995) presents itself in a chronic relapsing-remitting form, which is highly reminiscent of human disease. EAE is characterized by mild neurological signs and perivascular mononuclear cell infiltrates, large foci of primary demyelination, and reactive astrogliosis.

In contrast to the available information on clinical presentation and pathology of EAE, only little is known about the immunopathogenesis of EAE in non-human primates in general, and in this new model in particular. We have therefore analysed the expression of immunologically relevant molecules, both cytokines and accessory molecules, which are expressed in the CNS during periods of active EAE in marmoset monkeys. Strong expression of CD40 and $\mathrm{CD} 40 \mathrm{~L}+$ cells are found in perivascular mononuclear cell infiltrates throughout the white matter, suggesting that local CD40-CD40L interactions contribute to autoimmune effector mechanisms. In addition, pro-inflammatory and anti-inflammatory cytokines are simultaneously expressed within the same lesion during active EAE, similar to findings in MS autopsy brain. Our data provide further insight into the immunopathogenesis of EAE and MS, and broaden the rational basis for development of experimental therapies interfering with the functions of cytokines and accessory molecules, which can be evaluated in this model. 


\section{Materials and methods}

\subsection{Animals}

Marmoset monkeys (C. jacchus) bred at the Biomedical Primate Research Centre (BPRC) were kept under conditions approved by Dutch laws on animal experimentation. Experimental protocols were approved by the Institutional Animal Care and User Committee (IACUC/DEC) after scientific as well as ethical evaluation. Male animals EB, $\mathrm{EC}$ and EE were 4, 5, and 3 years of age respectively, at the start of the experiment. Female marmosets ED and EG were 3 years old. Animal CW, a female animal of 5 years old suffering from epilepsy, was used as a negative control with neurological disease other than EAE/MS.

\subsection{Induction of EAE}

EAE was induced essentially as described previously (Massacesi et al., 1995). Per animal, $20 \mathrm{mg}$ of human myelin (Van Noort et al., 1994) in PBS was emulsified with an equal volume of complete Freund's adjuvant, containing $3 \mathrm{mg} / \mathrm{ml}$ of Mycobacterium tuberculosis (H37 RA strain). Intracutaneous injections of $150 \mu$ l were divided over four sites on the dorsal axillary and inguinal regions. On the day of immunization and two days later, $10^{10}$ heat-inactivated Bordetella pertussis organisms were administered i.v. per kg body weight. Animals were sacrificed during active disease periods (see Fig. 1) by means of deep sedation with ketamin and intracardiac administration of pentobarbital. At necropsy one hemisphere was snap-frozen in liquid nitrogen for immunocytochemistry and the other hemisphere was fixed in formalin followed by paraffin embedding for histopathological examination.

\subsection{Clinical evaluation}

Severity of EAE was evaluated daily using a modification of the scoring system described by Massacesi et al. (1995). Development of EAE was monitored daily by a trained observer and the mean score reached in a particular week was taken as the readout number. It should be noted that EAE clinical scoring systems in general are not ordinal. However, the grading system for the marmoset is based on the fact that the disease course usually follows the sequence listed below, i.e., apathy preceeds lethargy and so on. Mean scores over a week are used to rule out incidental peak values which occur for only one day, or during only a part of a given day.

Clinical score:

0 no disease

0.5 apathy, loss of appetite, altered limb usage without ataxia (coordination weakness when walking)

1.0 lethargy, anorexia/weight loss, tremors

2.0 ataxia
2.5 incomplete paralysis on one side (hemiparesis) or both sides (paraperesis) of the body, sensory loss, brain stem syndrome or blindness

3.0 complete paralysis on one (hemiplegia) or both (paraplegia) sides of the body

4.0 compete paralysis of all four limbs

\subsection{Histopathological evaluation}

Histopathological evaluation was performed on sections of paraffin-embedded brain material routinely stained with hematoxylin/eosin, Klüver Barrera myelin stain, and Bielschowsky silver impregnation for visualization of axons. Parameters evaluated included extent of inflammation, composition of the infiltrate, extent of demyelination, activity of plaques and sites of the brain involved (see Section 3 for details). Demyelination was scored on multiple (10) cross-sections of spinal cord and 6 coronal sections through the brain. In case of minimal loss of myelin fibers, the score was $+/-$. When most lesions contain only perivenular demyelination, the score was + . A score of ++ indicates confluent demyelination: in addition to perivenular demyelination, plaques have formed in which demyelination involves several blood vessels.

\subsection{Immunocytochemistry}

Immunocytochemistry was performed on frozen sections of marmoset brain to detect expression of cell type specific markers, accessory molecules and cytokines (see below for description). The methodology of immunocytochemical procedures used here has been reviewed in detail previously (Claassen and Jeurissen, in press; Hoefakker et al., 1995). In brief, frozen sections of $8 \mu \mathrm{m}$ were thawmounted on silane coated glass slides and stored overnight in humidified atmosphere. The next day, sections were air-dried for $1 \mathrm{~h}$ and fixed at room temperature in fresh acetone containing $0.02 \%(\mathrm{v} / \mathrm{v}) \mathrm{H}_{2} \mathrm{O}_{2}$. After air-drying for 10 min, sections were washed with PBS and incubated with predetermined optimal dilutions of appropriate reagents (see below). Specificity of all antibodies had been evaluated previously on human material by combinations of ELISA, flow cytometry, and immunocytochemistry. The latter included inhibition experiments with recombinant protein. In addition, cross-reactivity with marmoset cytokines was assessed by staining of marmoset spleen sections.

Fixed sections were incubated with primary reagents overnight at $4^{\circ} \mathrm{C}$, in humidified atmosphere. Incubations with secondary and tertiary reagents were done during $1 \mathrm{~h}$ at room temperature. Between incubation steps, three washes with PBS were done. Biotinylated antibodies followed by avidin-peroxidase or avidin-alkaline phosphatase (Sigma, St. Louis, MO) were used for detection of IL-1 $\alpha$, IL-1 $\beta$ and IL-10. Unconjugated antibodies were used to detect IL-2, TNF- $\alpha$, IFN- $\alpha$ and IFN- $\gamma$. The 
secondary antibody was horse anti-mouse IgG biotin (Vector Lab., Peterborough, UK), and avidin-peroxidase was used as the final step. Incubation with AEC (3-amino-9ethylcarbazole) substrate for $10 \mathrm{~min}$ was used to reveal peroxidase activity (bright red translucent precipitate). After washing, sections were counterstained with hematoxylin, and embedded with glycerol-gelatin. Primary antibody/reagent omission control stainings were performed for the different secondary/tertiary reagents used.

For histochemical revelation of acid phosphatase activity, fixed sections were incubated for $30 \mathrm{~min}$ at $37^{\circ} \mathrm{C}$ with the appropriate substrate. This consisted of naphtyl ASBI-phosphate and pararosanilin in sodium acetate/barbital sodium buffer. Double staining for co-expression of CD40 on the cell membrane (in blue) and cytoplasmic acid phosphatase activity (in red) was performed by staining for CD40 as above, but staining for acid phosphatase prior to the final substrate step for alkaline phosphatase activity (using naphtol-AS-MX-phosphate and Fast Blue BB base).

\subsection{Reagents for detection of accessory molecules and cytokines}

Human-specific reagents used for detection of accessory cells and cytokines in marmosets are listed below. Cellular sources of cytokines and their roles in MS and EAE are reviewed in detail by Olsson, 1995, Liles and Van Voorhis, 1995 and Brosnan et al., 1995). References with respect to functions of accessory molecules in MS and EAE can be found for instance in Arima et al., 1996; Grewal et al., 1996 and Racke et al., 1995. Staining for acid phosphatase by means of the appropriate substrate detects activity of this enzyme in lysosomes in cells of the monocytic lineage, including monocytes/macrophages and microglia. As such, it is a useful marker to detect infiltrating macrophages within perivascular infiltrates of mononuclear cells. Expression of MHC-DR on antigen presenting cells (APC) and involved in presentation of (auto)-antigens was detected by means of MAb L234 (mouse IgG1)(kind gift of Dr. A. Morgan, Celltech, Slough, U.K.). CD40 as expressed on APC and involved in costimulation of both T cells and APC, was detected by means of MAb's 5D12 (mouse IgG2b) and M2 (mouse IgG1)(PanGenetics BV). CD40L as expressed on activated CD4 $+\mathrm{T}$ cells and involved in costimulation of both $\mathrm{T}$ cells and APC was detected by means of MAb M79 (mouse IgG1)(kindly provided by Immunex, Seattle, WA). B7-1 (CD80), expressed on APC and presumably involved in costimulation promoting Th1-type responses, was detected by means of MAb 5B5D1 (mouse IgG1)(a kind gift of Innogenetics N.V., Gent, Belgium). B7-2 (CD86), expressed on APC and presumably involved in promoting Th2-type responses, was detected using MAb 1G10H6 (mouse IgG2a)(a kind gift of Innogenetics N.V., Gent, Belgium). IFN- $\alpha$, expressed by B cells, NK cells and macrophages, and stimulating MHC class I expression was detected by means of MAb MC16 (mouse IgG1)(a kind gift of Dr. P. van der Meide, BPRC). IFN- $\gamma$, expressed by $\mathrm{T}$ cells, NK cells, macrophages, microglia and astrocytes, and presumably involved in stimulation of inflammation and expression of MHC class I and II was detected by antibody MD2 (mouse IgG1)(also a gift from Dr. P. van der Meide). TNF- $\alpha$, expressed by $\mathrm{T}$ cells macrophages, endothelial cells, microglia, oligodendrocytes and astrocytes, can stimulate cytokine secretion and may have direct degradating effects on myelin. TNF- $\alpha$ was detected by means of MAb 61E71 (mouse IgG1)(also a gift from Dr. P. van der Meide). IL- $1 \alpha$ and IL- $1 \beta$ were detected by MAb VMP18 (mouse IgG1) and VHP20 (mouse IgG2a), respectively (Instituto Ricerche Immunobiologiche [IRIS], Siena, Italy). These cytokines can be produced by macrophages, $\mathrm{T}$ and B cells, NK cells, endothelial cells, microglia and astrocytes. They have pro-inflammatory effects and costimulate activation, maturation and clonal expansion of $\mathrm{T}$ and $\mathrm{B}$ cells, increase expression of ICAMs and have chemotactic activity for macrophages and neutrophils. IL-2 produced by $\mathrm{T}$ cells and astrocytes promotes proliferation and activity of antigen-specific B and T cells. IL- 2 was detected by means of MAb 80-3418-01 (mouse IgG1)(Genzyme, Naarden, Netherlands). IL-4 produced by Th2 cells, macrophages and B cells stimulates activation and proliferation of B cells, secretion of immunoglobulins, proliferation of $\mathrm{T}$ cells, inhibits development of Th1 cells and stimulates development of Th2 cells, and upregulates MHC class II expression on macrophages and stimulates phagocytic activity. IL-4 was detected by means of MAb 1842-01 (mouse IgG1)(Genzyme). IL-10 produced by Th2 cells, macrophages, B cells and astrocytes suppresses macrophage function and pro-inflammatory cytokine production by macrophages, thereby reducing Th1 cytokine production, it downregulates MHC class II expression, and increases B cell proliferation. IL-10 was detected by means of MAb MCA B-S10 (mouse IgG1)(Instruchemie, Hilversum, Netherlands). IL-12 can be expressed by macrophages and B cells, promotes growth of T cells and NK cells, and displays anti-inflammatory activity. Expression of the p35 chain of IL-12 was detected by MAb 1841-D (mouse IgG1)(Pharmingen, San Diego, CA).

\subsection{Evaluation and quantitation of immunocytochemistry}

Two to three independent stainings on two to four sections were done for each marker, leading to a total of 4-9 brain sections per animal, and antibody immunocytochemical stainings of all individual sections were evaluated by two independent observers, using semi-quantitative scoring criteria based on previously published systems (Massacesi et al., 1995; Windhagen et al., 1995)(see legend of Table 2). Staining intensity, as described in the legend of Table 2, refers to the presentation of individual positively-stained cells. Although staining intensity does not necessarily reflect physiological importance of the 

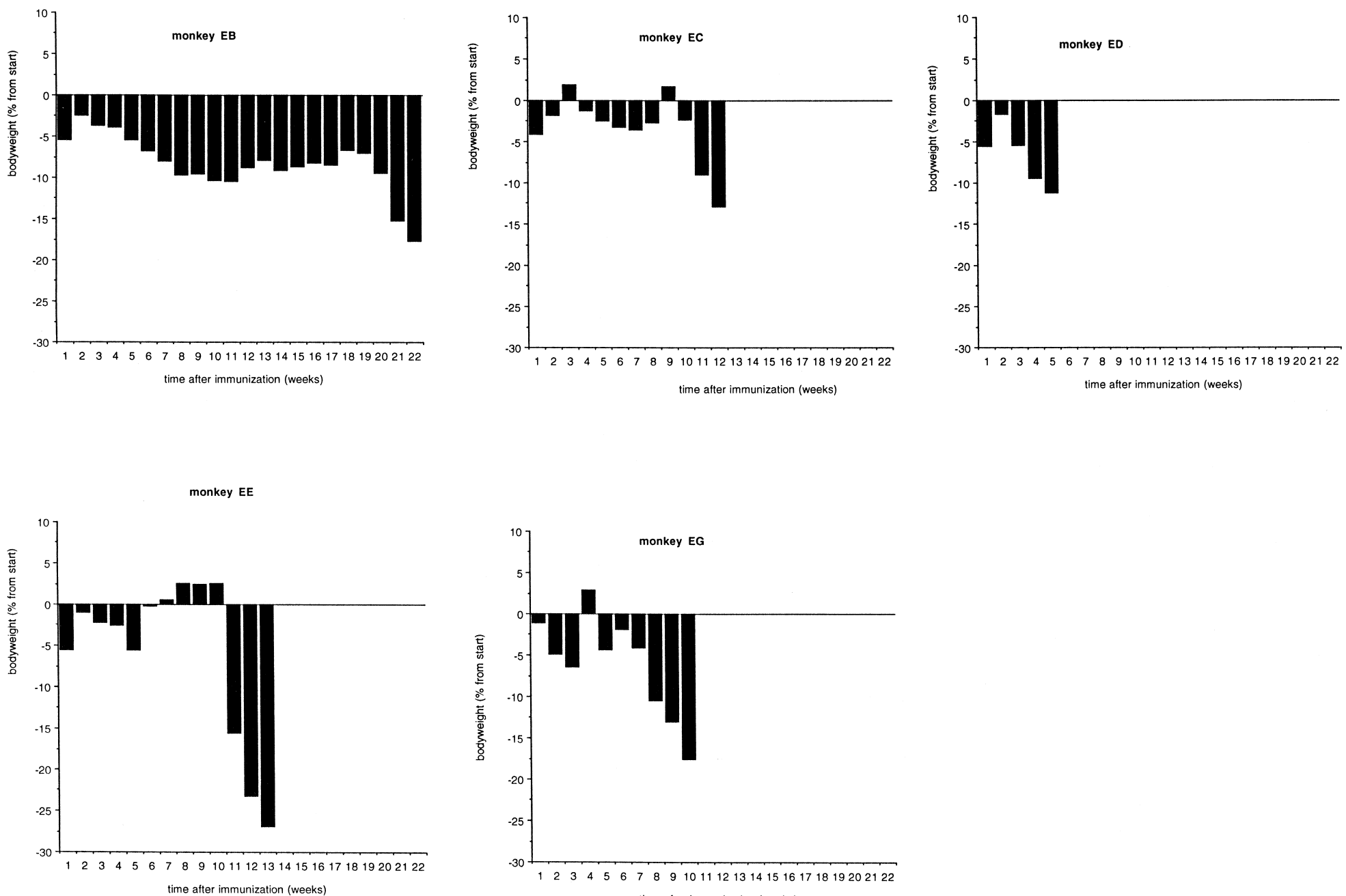

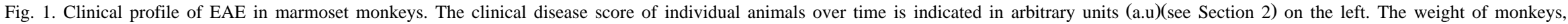
expressed as a percentage of the animal's weight at the start of the experiment is indicated on the right. 

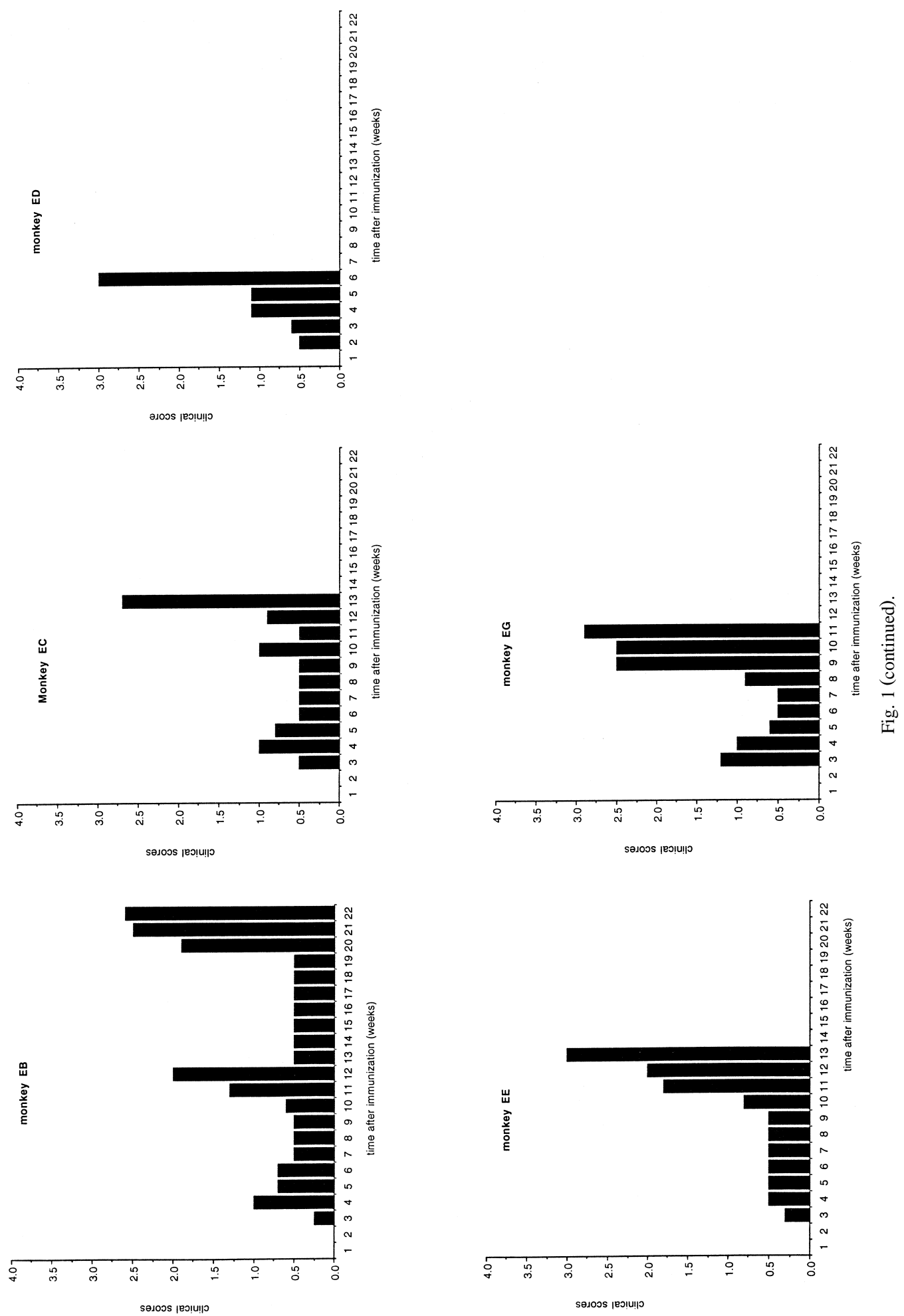
presence of a molecule, it does give information on the local expression level.

For evaluation and quantitation of stainings, as well as for photomicrographs, an Olympus Vanox brightfield photomicroscope was used.

\section{Results}

\subsection{Clinical profile of EAE in marmoset monkeys}

All five animals developed disease two to three weeks after immunization (100\% incidence), with an individually different course of the disease (Fig. 1). Active inflammation of the brain was confirmed with MRI (manuscript in preparation). In addition, all animals eventually progressed to strong clinical disease (clinical score 2 or higher). Moderate to marked weight loss was observed (from 10\% up to $27 \%$ in animal EE), which mirrored the severity of the clinical signs. Animal EB, which was followed for 22 weeks post-induction, had three disease periods of increasing severity. Animals EC and EG followed a similar pattern, but were followed for a shorter period of time and had two bouts of active disease. ED developed particularly rapid and aggressive disease, reaching score 3 within 6 weeks. Animal EE developed limited signs of disease at first, and then had one severe attack accompanied by major weight loss, before euthanasia. Animals were sacrificed at different time points after disease induction, but always during active disease.

\subsection{Histopathology of EAE brain}

Since animals were all euthanized during an active disease period, albeit at different time points after disease induction, the subsequent analysis of brain tissue by histopathology and immunocytochemistry was expected to reflect active engagement of cytokines and accessory molecules in ongoing local autoimmune responses.

As expected, histopathological evaluation of marmoset brains affected by active EAE showed multiple foci of inflammation and myelin loss (Table 1). All animals displayed inflammatory perivascular infiltrates, but to varying extents. Different stages of lesion formation were found within each animal, scattered throughout the brain white matter. Lesion formation ranged from small perivascular cuffs of infiltrating mononuclear cells to large confluent lesions with necrotic centers, the latter mainly located around the ventricles. Infiltrates consisted of lymphocytes and monocytes/macrophages, as has been described for human MS and rodent EAE models. Granulocytes were only present by exception (animal EG). Staining for acid phosphatase activity, a lysosomal enzyme characteristic for cells of the monocytic lineage, revealed sometimes massive numbers of perivascular infiltrating macrophages and activated microglia (see also Fig. 2a-d). Varying levels of myelin loss were found, where EE was notably extreme. In this animal, in spite of brain inflammation, no myelin loss or active demyelination were evident despite the fact that this animal had strong clinical disease and a severe reduction in body weight. As in human MS, the optic system was affected in three out of five animals. The sciatic nerve did not show evidence of inflammation. In two animals a moderate degree of inflammation was present in the spinal cord.

\subsection{In situ expression of accessory molecules}

To assess whether different accessory molecules are expressed in the brain during EAE, immunocytochemistry was performed on frozen sections. We focused on CD40CD40L and B7-1/B7-2 (CD80/CD86) in view of the proposed roles of those molecules in EAE and MS (see Cross et al., 1995; Khoury et al., 1995; Kuchroo et al., 1995; Miller et al., 1995; Perrin et al., 1995; Racke et al.,

Table 1

Histopathology of EAE brain

\begin{tabular}{llllllllll}
\hline Animal & Inflam. & Infiltrate & Macrophages & Myelin loss & Active & Brain & Spinal cord & Roots & N. Ischiadicus \\
\hline EB & ++ & Ly, Mo & + & ++ & $\pm^{a}$ & Opt, Fo & +++ & - \\
EC & ++ & Ly, Mo & +++ & + & + & CSO, Opt & ++ & - \\
ED & + & Ly, Mo & ++ & \pm & + & CSO, CWM & + & - \\
EE & + & Ly, Mo & +++ & - & - & CSO, Opt & meninges & + \\
EG & +++ & G/Ly, Mo & +++ & ++ , destructive & + & CSO, Thal & +++ & + & - \\
\hline
\end{tabular}

Abbreviations: CSO, centrum semiovale (periventricular white matter); CWM, cerebellar white matter; Fo, fornix; G, granulocytes; Inflam., inflammation; Ly, lymphocytes; Men, meninges; Mo, monocytes /macrophages; Opt, optic system; Thal, thalamus; Inflammation score: 0, no inflammation present; + rare, (1-3) perivascular cuffs /average whole section; ++ , moderate numbers $(3-10)$ of perivascular cuffs /section; +++ , widespread perivascular cuffing and parenchymal infiltration by inflammatory cells.

Macrophages: number of infiltrates with acid phosphatase activity. Acid phosphatase activity is found in macrophages and activated microglia.

Demyelination: \pm , single demyelinated fibers; + perivenous demyelination; ++ confluent demyelination.

Active: lesional activity as defined by the presence of macrophages containing myelin degradation products.

${ }^{a}$ Active lesions were only present in the spinal cord, and not in the brain.

Spinal cord: - , no involvement; + , limited involvement; ++ , moderate involvement; +++ extensive involvement.

Roots: - , no involvement; + , involvement of roots.

N. ischiadicus: - , no involvement; + , involvement of nerve. 
1995; Arima et al., 1996). The results of immunocytochemical stainings are summarized in Table 2, and are discussed below. Specific stainings were interpreted in light of the corresponding negative control staining (omission of the primary antibody). In general, negative control stainings done by omission of the primary antibody revealed little or no staining. Animal $\mathrm{CW}$, which suffered from a non-inflammatory neuropathy, i.e., epilepsy, was used as a non-EAE CNS-disease control. No or only very limited expression of accessory molecules was found in this brain tissue.

\subsection{1. $M H C-D R$}

Expression of MHC class II, although not an accessory molecule sensu stricto, was evaluated because of its pivotal role in antigen presentation to $\mathrm{CD} 4+\mathrm{T}$ cells, proximal to expression of inducible accessory molecules on $\mathrm{T}$ cells and antigen presenting cells (such as CD40L, B7-2 and CTLA4: see Roy et al., 1995 and Jaiswal et al., 1996). EAE-animals showed mononuclear cells with high levels of expression of MHC-DR in all infiltrates. Staining was mostly restricted to the perivascular infiltrates. In addition to large infiltrates, animal EC had many small clusters of positive cells, and also showed some scattered positive cells in the parenchyma, possibly representing infiltrating macrophages or microglia. In the epilepsy control animal $\mathrm{CW}$, a minimal number $(<5)$ of scattered positive cells was found per section. Fig. 2(i) shows an example of MHC-DR expression in EAE. The pattern of expression found is consistent with findings in human MS and rodent models, where class II is mainly found on macrophages, and supports the view that local interaction between antigen-presenting cells and effector cells (macrophages and $\mathrm{T}$ cells) contributes to inflammation.

\subsection{2. $C D 40$}

Four out of five EAE animals had strong expression (EC, ED, EE, EG) or moderate expression of CD40 on high numbers of mononuclear cells within multiple infiltrates. Not all infiltrates contained CD40-positive cells, possibly pointing at differential expression of this accessory molecule in lesions of different age. CD40 was not present in sections of animal EB despite active disease and myelin loss. Animals EE and EG displayed some strongly positive cells scattered around infiltrates, possibly representing infiltrating macrophages or local microglia. Intense CD40 expression was found in large infiltrates as well as in small cell clusters.

It has been reported that CD40 can be functionally expressed on endothelium under inflammatory conditions (Hollenbaugh et al., 1995; Karmann et al., 1995). Interestingly, the 5D12 antibody used here to detect CD40 did not reveal endothelial expression of this molecule. However, anti-CD40 MAb M2 did stain limited numbers of endothelial cells in animals EC and ED, and more numerous endothelial cells in EE and EG. Apparently, these two
MAb recognize differentially accessible epitopes on CD40. This is supported by distinct activities of these MAb in in vitro assays as well (Kwekkeboom et al., 1993). CD40 was not expressed in control animal CW. Examples of CD40 expression are shown in Fig. 2c,d.

\subsubsection{Co-expression of CD40 and acid phosphatase}

To assess whether CD40 within perivascular infiltrates is expressed by cells of the monocytic lineage, similar to MS in humans (Gerritse et al., 1996), double staining for cell surface CD40 expression and intracytoplasmic acid phosphatase activity was performed (see Fig. 2d for an example). In general, in several animals, many double staining cells were found. CD40 expression by infiltrating macrophages was not a strict rule as cells single positive for acid phosphatase could also be found. In addition, CD40 single positive cells were sometimes found, which may represent infiltrating B cells. Animal EB did not show extensive infiltration of the brain by macrophages (see also Table 1). Brain sections of animal EC contained abundant double staining cells, both in small and in larger infiltrates. In addition, single positive acid phosphatase containing cells co-localized with CD40 single positive cells. In animal ED, the majority of acid phosphatase expressing cells did not express CD40 on the membrane, but a significant fraction co-expressed CD40 and acid phosphatase. Animal EE could not be evaluated because of the absence of infiltrates in the material available for this staining. Animal EG showed abundant and brightly double stained cells (Fig. 2d), and again many cells singly positive for acid phosphatase were found. A minority of CD40 single positive cells was also found.

\subsection{4. $C D 40 L$}

CD40L was expressed in brain sections from four out of five animals with EAE, with the exception of animal EB. Compared to expression of CD40, CD40L was present at a much lower level, both with respect to the number of positive cells, and the staining intensity of individual cells. Fewer infiltrates contained CD40L-positive cells, the frequency of positive cells per infiltrate and the staining intensity per cell were considerably lower than of those expressing CD40. Fig. 2e shows a rare example of more abundant expression of $\mathrm{CD} 40 \mathrm{~L}$ within an infiltrate, whereas Fig. 2f shows the more common pattern of scattered cells with low expression of CD40L.

\subsection{5. $C D 80 / B 7-1$ and $C D 86 / B 7-2$}

B7-1 expression was limited in terms of number of animals, number of infiltrates, number of positive cells per infiltrate, and intensity of staining. An example is shown in Fig. 2g. Compared to B7-1, B7-2 was expressed in more animals (four out of five), and positive infiltrates as well as cells were more frequent (Fig. 2h). However, compared to frequency and level of expression of CD40, B7-2 expression was quite low. 

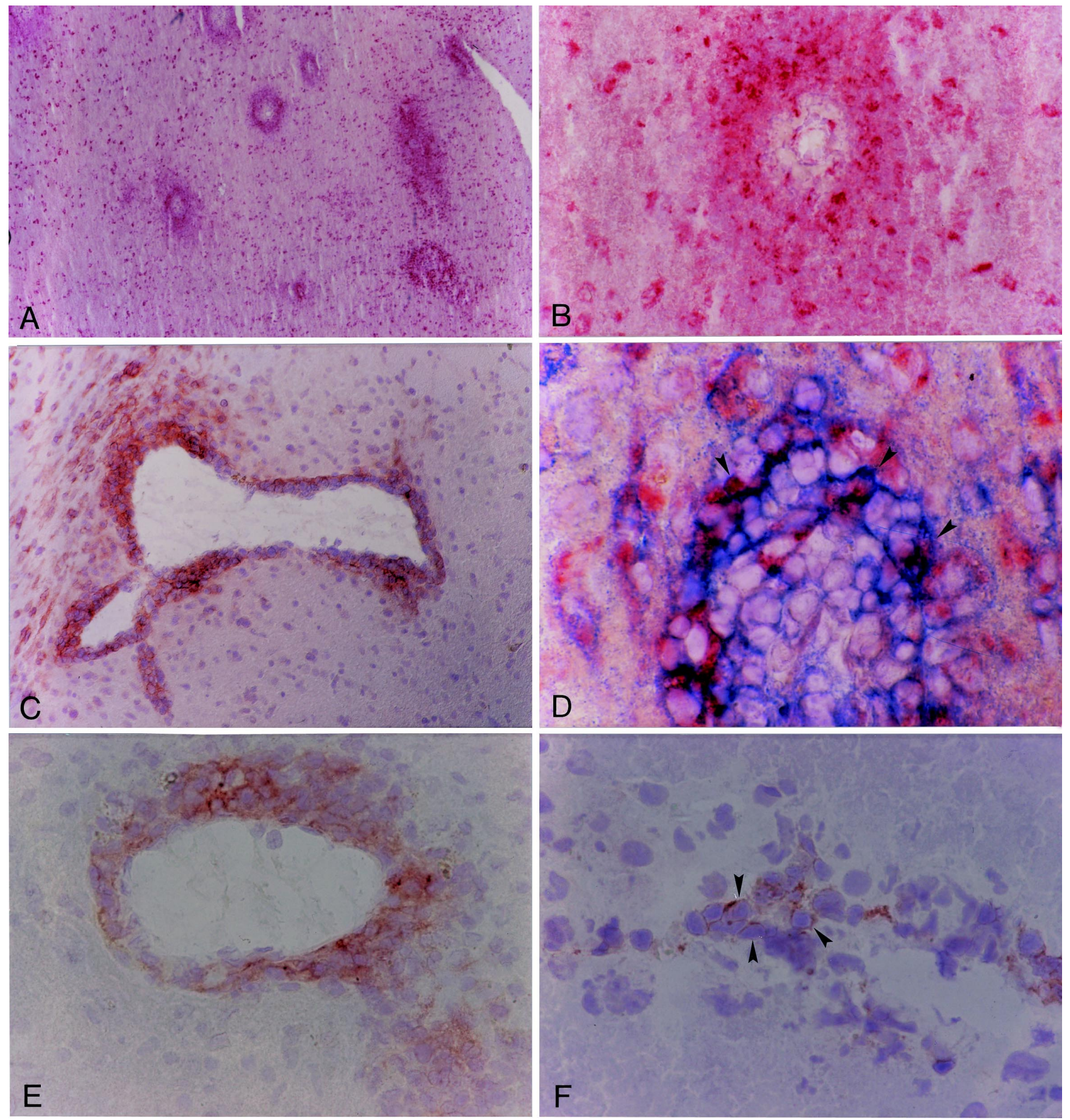

Fig. 2. Expression of accessory molecules and cytokines in marmoset EAE brain. (a) Acid phosphatase (red) expressed by infiltrating macrophages and activated microglia. Low power magnification of a brain section animal EG $(\times 40)$; (b) Detail of (a), showing extensive perivascular infiltration by macrophages (red) $(\times 200)$; (c) CD40 (red) expressed on infiltrating mononuclear cells (animal EG) $(\times 100)$; (d) Doublestaining showing macrophages with cytoplasmic acid phosphatase activity (red) and membrane CD40 expression (blue)(animal EG). Arrowheads indicate examples of macrophages expressing CD40 ( $\times 650)$; (e) CD40L (red) expressed on perivascular mononuclear cells (animal EE) $(\times 200)$; (f) Scattered CD40L-expressing cells (red) within an infiltrate (animal ED) $(\times 325)$; (g) Limited expression of B7-1 (arrowheads indicate examples)(animal EC) $(\times 325)$; (h) Expression of B7-2 (arrowheads)(animal EE) $(\times 130)$; (i) Strong expression of MHC-DR in all infiltrates of all EAE animals (animal EE) $(\times 200)$; (j) Locally restricted expression of IL-12 within an infiltrate: compare with (b) (both animal EG) $(\times 325)$; (k) Expression of IL-1 $\beta$ in a small infiltrate in animal EC $(\times 325)$; (l) Abundant expression of IL-10 by cells of astrocyte morphology, surrounding a perivascular infiltrate (animal EC) $(\times 200)$. Details of staining reagents and protocols are listed in Section 2. 

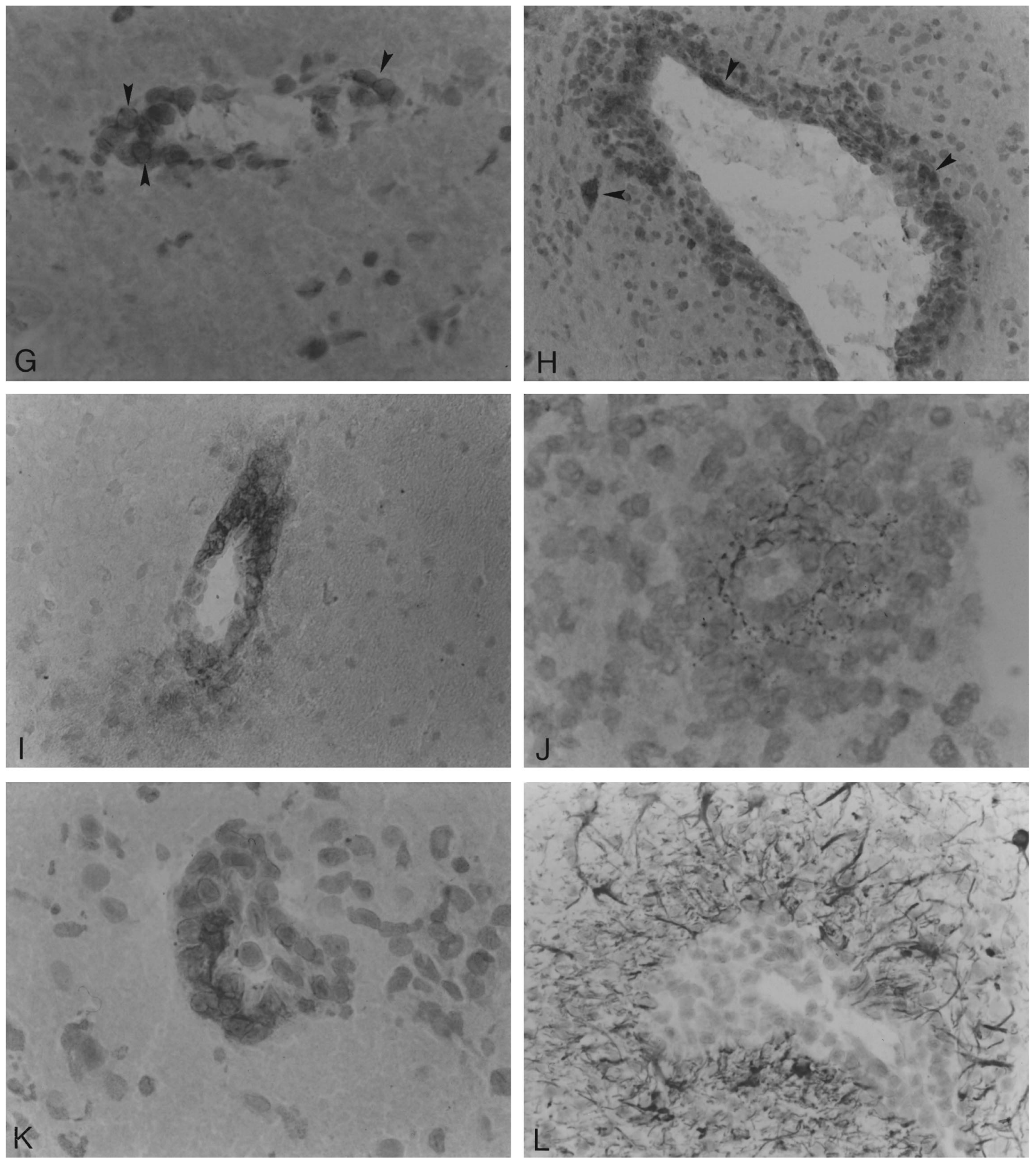

Fig. 2 (continued).

\subsection{In situ expression of cytokines}

The expression of different pro-inflammatory and antiinflammatory cytokines previously found in the CNS of MS-patients and in rodents with EAE was also investigated in marmosets by means of immunocytochemistry.
Results for the infiltrates are summarized in Table 3 and are discussed below. The epileptic animal $\mathrm{CW}$ was used as a non-inflammatory neuropathy control. Some staining associated with the endothelium and inner cell layers directly surrounding blood vessels was found for some cytokines. Expression of IFN- $\alpha$, IL- $1 \alpha$ and IFN- $\gamma$ was 
Table 2

Accessory molecules expressed by mononuclear cells infiltrating the brain $^{\mathrm{a}}$

\begin{tabular}{llllllll}
\hline Molecule & \multicolumn{9}{c}{ Animal } \\
\cline { 3 - 7 } & & EB & EC & ED & EE & EG & CW \\
\hline MHC-DR & number & ++ & +++ & +++ & +++ & +++ & - \\
\multirow{2}{*}{ CD40 } & intensity & ++ & ++ & ++ & ++ & ++ & - \\
& number & - & +++ & ++ & +++ & +++ & - \\
CD40L & intensity & - & ++ & + & ++ & ++ & - \\
& number & - & +++ & ++ & + & ++ & - \\
B7-1/CD80 & intensity & - & + & + & + & + & - \\
number & - & ++ & - & + & + & - \\
B7-2/CD86 & intensity & - & + & - & + & + & - \\
& number & - & +++ & ++ & ++ & + & - \\
& intensity & - & + & + & $+/++$ & + & - \\
\hline
\end{tabular}

${ }^{a}$ Inflammatory infiltrates were scored with respect to both numbers and size based on staining for acid phosphatase activity (cells of the monocytic lineage, excluding reactivity in parenchymal microglia) as follows. Numbers: infiltrates; - , no infiltration; + , occasional perivascular cuffs (1-3) on average per section; ++ , moderate number of perivascular cuffs (4-10) on average per section; +++ , large number of perivascular cuffs $(>10)$ per section and infiltration of the parenchyma by acid phosphatase-positive cells. Size: maximum size score of infiltrates determines final score: + , small infiltrates (up to 30 cells); ++ , medium-sized infiltrates (30-100 cells); +++ , large infiltrates (more than 100 cells). Expression of accessory molecules and cytokines was separately evaluated for endothelium and the cell layers directly adjacent to the endothelium, and the infiltrates. Only data for the infiltrates are shown in Table 2. Numbers of positive cells and staining intensity of individual cells is shown as follows: Numbers: - , no positive cells; + , occasional perivascular cuffs $(1-3)$ containing positive cells on average per section; ++ , moderate numbers of perivascular cuffs (4-10) containing positive cells; +++ , large number $(>10)$ of perivascular cuffs containing positive cells. Intensity: + , positive cells with low to moderate staining intensity; ++ , positive cells with high staining intensity.

strong in this location in all EAE animals, whereas TNF- $\alpha$ expression was more limited. IL- $1 \beta$ was expressed at a low level in this location in EAE animals EB and EC. IL-2 was expressed at low levels in animals EC, ED, EE, and EG. IL-12 was found in animals ED and EE. In control animal $\mathrm{CW}$, strong expression of IFN- $\gamma$ was found here, as well as a limited expression of IFN- $\alpha$, TNF- $\alpha$, and IL- $1 \alpha$, but no other cytokines.

Expression of cytokines by cells infiltrating the brain parenchyma or by glia cells was found for IL-10 in all EAE animals, but only strongly in animal ED. Control animal CW also showed occasional IL-10 expressing cells in the parenchyma. Occasional IL- $1 \beta$ expressing cells were only present in the parenchyma of animal EB. IL-4 was only found in the parenchyma in animal EG, but at relatively high levels.

\subsubsection{IFN- $\alpha$ and IFN- $\gamma$}

IFN- $\alpha$ was expressed on cells within multiple perivascular infiltrates in all animals. Expression was minimal in animal EB, while EC and ED showed numerous infiltrates with strongly positive cells. The pattern and extent of IFN- $\gamma$ expression was very similar to that of IFN- $\alpha$.

\subsection{2. $T N F-\alpha$}

TNF- $\alpha$ expression was more limited than IFN- $\alpha$ and IFN- $\gamma$, and staining intensity of individual cells was lower. Again, animal EB had the lowest expression of the EAEaffected marmosets, but ED and EE also displayed low levels.

\subsection{3. $I L-1 \alpha$ and $I L-1 \beta$}

Extensive expression of IL- $1 \alpha$ was found in all EAE animals, with high staining intensity in all EAE animals except ED. Often, astrocyte-like cells in the parenchyma were positive. Compared to IL- $1 \alpha$, expression of IL- $1 \beta$ was somewhat more limited, with just a few infiltrates per section containing positive cells in animals ED and EE. Except in animal EC, staining intensity of individual cells was low. An example of IL- $1 \beta$ expressing cells is shown in Fig. 2k. In animal EB, astrocyte-like cells expressing IL- $1 \beta$ were also found.

\subsubsection{IL-2 and IL-4}

IL-2 was absent in infiltrates of EAE-affected marmosets EB and ED, while the other EAE animals had low (EC, ED) or moderate (EG) expression of IL-2. IL-4 expression was more limited than IL-2, being absent in animal EC and present at low levels in EB, ED and EE. In this case animal EG formed the exception with some infiltrates containing cells brightly positive for IL-4. In addition, this animal displayed individual IL-4 positive cells with astrocyte-like morphology, surrounding the infiltrates.

Table 3

Cytokines expressed by mononuclear cells in brain infiltrates ${ }^{\mathrm{a}}$

\begin{tabular}{|c|c|c|c|c|c|c|c|}
\hline \multicolumn{2}{|c|}{ Cytokine } & \multicolumn{6}{|l|}{ Animal } \\
\hline & & EB & $\mathrm{EC}$ & ED & $\mathrm{EE}$ & EG & $\mathrm{CW}$ \\
\hline \multirow[t]{2}{*}{ IFN- $\alpha$} & number & + & +++ & +++ & +++ & +++ & - \\
\hline & intensity & + & ++ & ++ & + & + & - \\
\hline \multirow[t]{2}{*}{ IFN- $\gamma$} & number & ++ & +++ & +++ & +++ & +++ & - \\
\hline & intensity & + & ++ & ++ & $+/++$ & + & - \\
\hline \multirow[t]{2}{*}{ TNF- $\alpha$} & number & + & +++ & ++ & ++ & +++ & - \\
\hline & intensity & + & + & + & + & ++ & - \\
\hline \multirow[t]{2}{*}{ IL-1 $\alpha$} & number & +++ & +++ & ++ & +++ & +++ & - \\
\hline & intensity & + & ++ & + & ++ & ++ & - \\
\hline \multirow[t]{2}{*}{ IL- $1 \beta$} & number & + & +++ & ++ & + & +++ & - \\
\hline & intensity & + & ++ & + & + & + & - \\
\hline \multirow[t]{2}{*}{ IL-2 } & number & - & ++ & - & ++ & +++ & - \\
\hline & intensity & - & + & - & + & + & - \\
\hline \multirow[t]{2}{*}{ IL-4 } & number & - & - & + & + & +++ & - \\
\hline & intensity & - & - & + & + & ++ & - \\
\hline \multirow[t]{2}{*}{ IL-10 } & number & +++ & +++ & +++ & ++ & +++ & + \\
\hline & intensity & ++ & ++ & ++ & ++ & ++ & + \\
\hline \multirow[t]{2}{*}{ IL-12 } & number & + & + & + & + & +++ & - \\
\hline & intensity & + & + & + & + & $+/++$ & - \\
\hline
\end{tabular}

${ }^{\mathrm{a}}$ See legend to Table 2 for quantitation criteria used. 


\subsection{5. $I L-10$}

IL-10 was expressed abundantly in most EAE animals with strong staining of individual cells. The general pattern was that cells surrounding perivascular infiltrates expressed high levels of IL-10. These cells had astrocyte-like morphology. Similar cells expressing IL-10 were found in the parenchyma surrounding the infiltrate. An example of this expression pattern is shown in Fig. 2k. Cannella and Raine have described a similar distribution of IL-10 expressing cells in human MS material (Cannella and Raine, 1995). In addition to this pattern, EAE animals often showed IL-10 expression within small infiltrates. In control animal CW (epilepsy control), some cells with astrocyte morphology in the brain parenchyma and around vessels stained positive for IL-10. This staining was clearly weaker and positive cells were much less frequent than in EAE animals.

\subsection{6. $I L-12$}

IL-12 was only expressed to a considerable extent in animal EG. An example of IL-12 staining is shown in Fig. $2 \mathrm{j}$. In this case, it is interesting to note that IL-12 production was restricted to a ring around the vessel, coinciding with an area where acid phosphatase activity was absent (compare Fig. 2b,j). This suggests that cells other than macrophages may produce IL-12 locally.

\section{Discussion}

This report documents the qualitative expression of a series of immunological key molecules in the CNS of EAE-affected animals. The main conclusions are that cytokine producing cells and cells expressing costimulatory molecules are present in perivascular mononuclear cell infiltrates, which is also the location where demyelination is found. High expression of CD40 is found and less pronounced expression of CD40L, B7-1 and B7-2.

\subsection{Clinical disease and histopathology}

The immunization protocol used induced strong disease in all five outbred animals of a relapsing-remitting nature in the animals followed for longer periods (Fig. 1). This is consistent with previous claims that EAE in marmosets in a clinical sense mirrors human relapsing-remitting MS. In general, we observed more severe disease than in the study of Massacesi et al. (1995). This may be due to different methods used to purify myelin for immunization, the genetic and microbiological status of the animals, or differences in the adjuvant and B. pertussis preparations. In our experience in rodent EAE models, seemingly minute modifications in induction protocols can result in markedly different disease activity. The fact that genetically distinct, outbred animals were used here may account for individual variation in kinetics and severity of disease.
As animals in this study were sacrificed during acute episodes of the disease, we assume that the tissues studied here only reflected events occurring during periods of clinically active disease. Histopathological evaluation of brain tissue revealed that all EAE-animals had inflammation and infiltration of the brain with lymphocytes and monocytes. Animal EG showed the most severe and extensive involvement of the brain, including infiltration with granulocytes, destructive myelin loss, and involvement of the roots. Animal EE was the only case without myelin loss or active demyelination, but with involvement of the roots. In classical MS, the disease process is restricted to the CNS. However, in Marburg's type of acute MS, inflammation and demyelination in peripheral nerves is common (Marburg, 1906). Importantly, in acute marmoset EAE, no involvement of the peripheral sciatic nerve was seen, indicating that the major pathological alterations are confined to the CNS. Collectively, the histopathological data are very similar to findings in human MS brain and thus, support the usefulness of marmosets as a model for MS also on this level.

\subsection{Correlations between clinical disease and im- munopathology}

The general picture emerging from our data is that clinically severe EAE is accompanied by strong inflammation of the brain, and myelin loss. MHC-DR and CD40 are strongly expressed, whereas expression of CD40L, B7-1 and B7-2 are much more limited. The level of cytokine expression roughly correlated with the number of infiltrating macrophages, with EC, EE, and EG having the highest local presence of cytokines. Pro-inflammatory and anti-inflammatory cytokines were co-expressed during marmoset EAE. This too, is in agreement with the expression pattern of cytokines observed in MS lesions (Woodroofe and Cuzner, 1993; Cannella and Raine, 1995; McFarland, 1995). Animal EB is clearly an exception to the rule, as this animal showed outspoken clinical disease (score around 2.5), considerable expression of MHC-DR, but none of the other accessory molecules. In addition, EB had minimal presence of the different cytokines evaluated. This difference could be due to the fact that in this animal, the bulk of the active lesions was found in the spinal cord. In the brain tissue that was used for evaluation of accessory molecules and cytokines, the limited number of lesions would preclude detection of these molecules.

\subsection{Accessory molecules: $C D 40-C D 40 L$}

We analyzed the role of accessory molecules in marmoset EAE in view of reports by us and others of their involvement in MS and EAE. CD40-CD40L interactions between CD40L on activated CD4 + T cells and CD40 on $\mathrm{B}$ cells, dendritic cells and follicular dendritic cells are crucial for the initiation of antibody responses against 
pathogens, isotype switching and memory formation (reviewed by Laman et al., 1996; Van Kooten and Banchereau, 1996). CD40 can also be functionally expressed on macrophages (Alderson et al., 1993), and mediates $\mathrm{T}$ cell-macrophage interactions (Wiley and Harmsen, 1995; Campbell et al., 1996; Kamanaka et al., 1996; Soong et al., 1996; Stout et al., 1996). CD40 is expressed during chronic inflammation in atherosclerotic plaques (Laman et al., 1997). CD40L also has a role in thymic selection of $\mathrm{T}$ cells (Foy et al., 1995), and CD40-CD40L interactions are involved in experimental autoimmune disease such as collagen-induced arthritis (Durie et al., 1993) and lupus nephritis (Mohan et al., 1995). Interestingly, recent studies in systemic lupus erythematosus (SLE) patients have shown that increased CD40L expression is involved in this clinical autoimmune condition (Desai-Mehta et al., 1996; Koshy et al., 1996).

By in vivo blocking experiments, we previously showed that CD40-CD40L interactions are crucial to development of EAE in SJL-mice. In addition, it was found that CD40 is abundantly expressed by infiltrating macrophages in autopsy brain material of MS-patients, while CD40L-expression is more limited (Gerritse et al., 1996). The current study demonstrates that analogous to MS, in marmoset EAE the brain is infiltrated by macrophages expressing high levels of CD40 (Fig. 2c,d). A minority of CD40-positive cells lacking acid phosphatase activity was found as well, which may represent B cells analogous to human MS brain. Although to a much lower extent than CD40, CD40L was also expressed locally (Fig. 2e,f). The low level of CD40L expression may partly result from the different downregulatory mechanisms described for this molecule (Yellin et al., 1994; Van Kooten and Banchereau, 1996).

In what ways may local interactions between CD40L on activated $\mathrm{T}$ cells and CD40 on macrophages contribute to disease? First, signals through CD40 are involved in T cell priming (Van Essen et al., 1995; Grewal et al., 1995; Grewal and Flavell, 1996; Grewal et al., 1996). In agreement with this, it was shown recently that production of both Th1 cytokines (IL-2, IFN- $\gamma$ ) and Th2 cytokines (IL-4, IL-5 and IL-10) by human T cells is strongly enhanced by CD40L ligation (Peng et al., 1996). Importantly, in progressive MS, activated CD4 + T cells stimulate increased IL-12 production (Balashov et al., 1997).

Second, activated $\mathrm{T}$ cells expressing CD40L can induce relevant macrophage effector functions. A multitude of studies, including in vivo depletion experiments, has shown that macrophages are crucial for development of EAE (Huitinga et al., 1995). Macrophages with different activation markers characterize demyelinating lesions of distinct stages in human MS-brain (Brück et al., 1995). Macrophages can contribute directly to myelin damage by a wide range of effector functions, such as production of cytokines, proteolytic enzymes, nitric oxide, reactive oxygen species, and lipid peroxidation. Macrophages can also indirectly affect the inflammatory process and demyelina- tion by expression of MHC class II, (auto)-antigen presentation, and secretion of compounds affecting other cell types.

Several studies have demonstrated that ligation of CD40 activates macrophage functions that potentially contribute to EAE and MS. CD40 ligation leads to adherence of macrophages to CD40L-expressing cells (Alderson et al., 1993), homotypic aggregation and increased survival of cells in culture (Kiener et al., 1995). CD40L induced increased expression of CD54 (ICAM-1), MHC class II, CD86 (B7-2) and CD40, improving the antigen presentation function of macrophages (Kiener et al., 1995). Functionally, CD40L supplied a costimulus for production of the pro-inflammatory cytokines TNF- $\alpha$, IL- $1 \beta$, IL-6, IL-8 and IL-12 (Alderson et al., 1993; Wagner et al., 1994; Kiener et al., 1995; Shu et al., 1995; Kennedy et al., 1996). Stuber et al. (1996) have shown that anti-CD40L MAb (MR1) inhibits IL-12 production in mice, which may prevent priming of Th1-cells. This mechanism may be responsible for the prevention of EAE induction in mice by anti-CD40L MAb reported previously (Gerritse et al., 1996). We found very limited IL-12 expression in EAE-affected marmosets (only animal EG), but this concerned IL-12p35. Kato et al. (1996) have shown that in the mouse, production of IL-12p40 but not p35 is regulated through CD40L.

With respect to non-cytokine effector mechanisms of macrophages, it has been shown that CD40L can enhance production of cytotoxic NO production by murine macrophages (Tian et al., 1995). The inducible form of NO-synthase (iNOS) is activated in macrophages in MS brain (Bagasra et al., 1995). CD40L, IL-12 and NO production are also linked in cell-mediated immunity against Pneumocystis carinii (Wiley and Harmsen, 1995) and Leishmania species (Campbell et al., 1996; Kamanaka et al., 1996; Soong et al., 1996).

\subsection{Accessory molecules: B7-1/B7-2}

Several studies have investigated whether B7-1 and B7-2 costimulation is involved in EAE/MS in the light of preferential Th1 vs. Th2 activation (Cross et al., 1995; Khoury et al., 1995; Kuchroo et al., 1995; Miller et al., 1995; Perrin et al., 1995; Racke et al., 1995). These studies are conflicting to some extent, probably partly due to the different experimental approaches used. Collectively, these studies do seem to support the hypothesis that B7-1 and B7-2 differentially signal development of Th1 and Th2 cells, respectively. B7-1 would therefore have a key role in initiation and perpetuation of Th1-mediated autoimmune diseases, such as MS/EAE. Windhagen et al. (1995) have evaluated expression of B7-1 and B7-2 in relation to IL-12 production in human MS brain. These authors found increased expression of B7-1 and IL-12p40 in acute MSplaques, particularly from early disease cases. B7-2 was expressed on macrophages both in inflammatory infarcts 
and MS lesions. In our marmoset EAE material, B7-1 expression was particularly low, and B7-2 somewhat higher but still very limited as compared to CD40. In this respect, our findings do not seem to support an inductive role of B7-1. Whether these different levels of expression translate into functional differences is of course unknown at this point.

\subsection{Cytokine expression in marmoset EAE}

Current views on the role of cytokines in MS/EAE hold that the cytokines IL- $1, \mathrm{IL}-2, \mathrm{TNF}-\alpha, \mathrm{TNF}-\beta$ and IFN- $\gamma$ contribute to inflammation and disease, whereas the cytokines IL-4, IL-10, IFN- $\beta$ and TGF- $\beta$ have anti-inflammatory properties. This correlates with Th1-Th2 preponderance. Sequential expression of these cytokines has been found during induction, overt disease and recovery (Brosnan et al., 1995; Olsson, 1995). However, in an extensive and detailed analysis of cytokine and adhesion molecule expression in MS lesions of different activation stages, Cannella and Raine (1995) did not identify any expression pattern specific for MS. Notably, simultaneous expression of pro-inflammatory and anti-inflammatory cytokines was found within individual lesions, arguing against simple straightforward relationships between expression and disease activity. Most likely, lesions of different age and activity with differential cytokine patterns can co-exist (see Brosnan et al., 1995 and McFarland, 1995, for more extensive discussion of these issues). It is of note that some anti-inflammatory cytokines such as IL-4 are essential for antibody production, and that autoantibodies synergize with pro-inflammatory $\mathrm{T}$ cells in lesion formation (Linington and Lassmann, 1987; Linington et al., 1992; Genain et al., 1995).

The data of the current study are consistent with the above in the sense that pro-inflammatory and anti-inflammatory cytokines were co-expressed in marmoset EAE brain during active disease. We did not evaluate kinetics of expression during course of the disease, as has been done in rodents, since we studied animals in active disease periods only. However, material did include brains from the first, second, and third attack of the disease. The experiments therefore, support the view that the balance of relative expression of disease-inducing cytokines and downmodulatory ones determines the level of clinical signs, more than sequential expression. Further improvement in the discrimination of early vs. late and active vs. inactive lesions will shed more light on the role of cytokines. We are investigating these issues using MRI-directed immunopathological approaches, using gadolinium enhancement of blood brain barrier damage as a marker for early development of lesions. The importance of detailed analysis of cytokine profiles in situ is underscored by recent data of Genain et al. (1996) that immune deviation therapy aiming to induce $\mathrm{T}$ cell tolerance induction can lead to unexpected fatal disease (see also McFarland, 1996).

\subsection{Conclusion}

This communication shows that EAE in marmosets allows evaluation of experimental therapies for MS targeting accessory molecules or cytokines. Safety and efficacy of novel therapeutic molecules which are suitable for use in humans, such as humanized monoclonal antibodies, recombinant cytokines and accessory molecules, or smallmolecule inhibitors, can be tested preclinically in this model. Collectively, our previous data (Gerritse et al., 1996) and the present findings argue that CD40-CD40L interactions are operational in peptide-induced EAE in mice, whole myelin-induced EAE in marmosets, and naturally occurring $\mathrm{MS}$ in humans. We propose that local CD40-CD40L interactions in the CNS form a target for therapy of MS at different levels. CD40-CD40L interactions can lead to local priming of $\mathrm{T}$ cells and cytokine production. In addition, effector functions of macrophages relevant to $\mathrm{EAE} / \mathrm{MS}$ may be triggered through CD40. Finally, local $\mathrm{T}-\mathrm{B}$ cell interactions may result in production of auto-antibodies. The challenge is to pinpoint which $\mathrm{T}$ cell and macrophage functions are indeed triggered by CD40-CD40L interactions in vivo, and whether and to what extent such interactions are antigen dependent. Based on such knowledge, CD40-CD40L targeted therapy of exacerbations may result in clinical benefit for multiple sclerosis patients.

\section{Acknowledgements}

The expert technical assistance of Bas Groen (Department of Pharmacology, TNO Prins Maurits Laboratorium, Rijswijk, Netherlands) in motoric and behavioural assays of marmosets is gratefully acknowledged. We thank Drs. Kees Lucas and Hans van Noort for critical reading of the manuscript. This work was supported by grants number 94-171 MS and 95-221 MS of the Netherlands Foundation for the support of MS Research (Stichting Vrienden MS Research) and by grant number CT94-0071 of the European Union Human Capital and Mobility Program.

\section{References}

Alderson, M.R., Armitage, R.J., Tough, T.W., Strockbine, L., Fanslow, W.C., Spriggs, M.K., 1993. CD40 expression by human monocytes: regulation by cytokines and activation of monocytes by the ligand for CD40. J. Exp. Med. 178, 669-674.

Arima, T., Rehman, A., Hickey, W.F., Flye, M.W., 1996. Inhibition by CTLA-4Ig of experimental allergic encephalomyelitis. J. Immunol. 156, 4916-4924.

Bagasra, O., Michaels, F.H., Zheng, Y.M., Bobroski, L.E., Spitsin, S.V., Fu, Z.F., Tawadros, R., Koprowski, H., 1995. Activation of the inducible form of nitric oxide synthase in the brains of patients with multiple sclerosis. Proc. Natl. Acad. Sci. U.S.A. 92, 12041-12045.

Balashov, K.E., Smith, D.R., Khoury, S.J., Hafler, D.A., Weiner, H.L., 1997. Increased interleukin 12 production in progressive multiple 
sclerosis: induction by activated CD4 $+\mathrm{T}$ cells via CD40 ligand. Proc. Natl. Acad. Sci. U.S.A. 94, 599-603.

Brosnan, C.F., Cannella, B., Battistini, L., Raine, C.S., 1995. Cytokine localization in multiple sclerosis lesions. Correlation with adhesion molecule expression and reactive nitrogen species. Neurol. 45, 16-21, Suppl. 6.

Brück, W., Porada, P., Poser, S., Rieckmann, P., Hanefeld, F., Kretzschmar, H.A., Lassmann, H., 1995. Monocyte/macrophage differentiation in early multiple sclerosis lesions. Ann. Neurol. 38, 788-796.

Campbell, K., Ovendale, P.J., Kennedy, M.K., Fanslow, W.C., Reed, S.G., Maliszewski, C.R., 1996. CD40 ligand is required for protective cell-mediated immunity to Leishmania major. Immunity 4, 283-289.

Cannella, B., Raine, C.S., 1995. The adhesion molecule and cytokine profile of multiple sclerosis lesions. Ann. Neurol. 37, 425-435.

Claassen, E., Jeurissen, S.H.M. (in press). A step by step guide to in situ immune response analysis of lymphoid tissues by immunohistochemical methods. In: Weir, D.M., Blackwell, C., Herzenberg, L., Herzenberg, L. (Eds.), Handbook of Experimental Immunology, 5th edn., Blackwell Scientific Publications.

Cross, A.H., Girard, T.J., Giacoletto, K.S., Evans, R.J., Keeling, R.M., Lin, R.F., Trotter, J.L., Karr, R.W., 1995. Long-term inhibition of murine experimental autoimmune encephalomyelitis using CTLA-4-Fc supports a key role for $\mathrm{CD} 28$ costimulation. J. Clin. Invest. 95, 2783-2789

Desai-Mehta, A., Lu, L., Ramsey-Goldman, R., Datta, S.K., 1996. Hyperexpression of CD40 ligand by B and T cells in human lupus and its role in pathogenic autoantibody production. J. Clin. Invest. 97, 20632073.

Durie, F.H., Fava, R.A., Foy, T.M., Aruffo, A., Ledbetter, J.A., Noelle, R.J., 1993. Prevention of collagen-induced arthritis with an antibody to gp39, the ligand for CD40. Sci. 261, 1328-1330.

Foy, T.M., Page, D.M., Waldschmidt, T.J., Schoneveld, A., Laman, J.D., Masters, S.R., Tygrett, L., Ledbetter, J.A., Aruffo, A., Claassen, E., Xu, J.C., Flavell, R.A., Ohen, S., Hedrick, S.M., Noelle, R.J., 1995. An essential role for gp39, the ligand for CD40, in thymic selection. J. Exp. Med. 182, 1377-1388.

Genain, C.P., Lee-Parritz, D., Nguyen, M.-H., Massacesi, L., Joshi, N., Ferrante, R., Hoffman, K., Moseley, M., Letvin, N.L., Hauser, S.L., 1994. In healthy primates, circulating autoreactive $T$ cells mediate autoimmune disease. J. Clin. Invest. 94, 1339-1345.

Genain, C.P., Nguyen, M.-H., Letvin, N.L., Pearl, R., Davis, R.L., Adelman, M., Lees, M.B., Linington, C., Hauser, S.L., 1995. Antibody facilitation of multiple sclerosis-like lesions in a non-human primate. J. Clin. Invest. 96, 2966-2974.

Genain, C.P., Abel, K., Belmar, N., Villinger, F., Rosenberg, D.P., Linington, C., Raine, C.S., Hauser, S.L., 1996. Late complications of immune deviation therapy in a nonhuman primate. Sci. 247, 20542057.

Gerritse, K., Laman, J.D., Noelle, R.J., Aruffo, A., Ledbetter, J.A., Boersma, W.J.A., Claassen, E., 1996. CD40-CD40 ligand interactions in experimental allergic encephalomyelitis and multiple sclerosis. Proc. Natl. Acad. Sci. U.S.A. 93, 2499-2504.

Grewal, I.S., Xu, J., Flavell, R.A., 1995. Impairment of antigen-specific T cell priming in mice lacking CD40 ligand. Nature 378, 617-620.

Grewal, I.S., Foellmer, H.G., Grewal, K.D., Xu, J., Hardardottir, F., Baron, J.L., Janeway, C.A., Flavell, R.A., 1996. Requirement for CD40 ligand in costimulation induction, $T$ cell activation, and experimental allergic encephalomyelitis. Sci. 273, 1864-1867.

Grewal, I.S., Flavell, R.A., 1996. A central role of CD40 ligand in the regulation of $\mathrm{CD} 4+\mathrm{T}$ cell responses. Immunol. Today 17, 410-414

Hoefakker, S., Boersma, W.J.A., Claassen, E., 1995. Detection of human cytokines in situ using antibody and probe based methods. J. Immunol. Meth. 185, 149-175.

Hollenbaugh, D., Mischel-Petty, N., Edwards, C.P., Simon, J.C., Denfeld, R.W., Kiener, P.A., Aruffo, A., 1995. Expression of functional CD40 by vascular endothelial cells. J. Exp. Med. 182, 33-40.

Huitinga, I., Ruuls, S.R., Jung, S., Van Rooijen, N., Hartung, H.-P.,
Dijkstra, C.D., 1995. Macrophages in T cell line mediated, demyelination and chronic relapsing experimental autoimmune encephalomyelitis in Lewis rats. Clin. Exp. Immunol. 100, 344-351.

Jaiswal, A.I., Dubey, C., Swain, S.L., Croft, M., 1996. Regulation of CD40 ligand expression on naive CD4 T cells: a role for TCR but not co-stimulatory signals. Int. Immunol. 8, 275-285.

Kamanaka, M., Yu, P., Yasui, T., Yoshida, K., Kawabe, T., Horii, T., Kishimoto, T., Kikutani, H., 1996. Protective role of CD40 in Leishmania major infection at two distinct phases of cell-mediated immunity. Immunity 4, 275-281.

Karmann, K., Hughes, C.C., Schechner, J., Fanslow, W.C., Pober, J.S., 1995. CD40 on human endothelial cells: inducibility by cytokines and functional regulation of adhesion molecule expression. Proc. Natl. Acad. Sci. U.S.A. 92, 4342-4346.

Kato, T., Hakamada, R., Yamane, H., Nariuchi, H., 1996. Induction of IL-12 p40 messenger RNA expression and IL-12 production of macrophages via CD40-CD40 ligand interaction. J. Immunol. 156, 3932-3938.

Kennedy, M.K., Picha, K.S., Fanslow, W.C., Grabstein, K.H., Alderson, M.R., Clifford, K.N., Chin, W.A., Mohler, K.M., 1996. CD40/CD40 ligand interactions are required for $\mathrm{T}$ cell-dependent production of interleukin-12 by mouse macrophages. Eur. J. Immunol. 26, 370-378.

Khoury, S.J., Akalin, E., Chandraker, A., Turka, L.A., Linsley, P.S., Sayegh, M.H., Hancock, W.W., 1995. CD28-B7 costimulatory blockade by CTLA4Ig prevents actively induced experimental autoimmune encephalomyelitis and inhibits Th1 but spares Th2 cytokines in the central nervous system. J. Immunol. 155, 4521-4524.

Kiener, P.A., Moran-Davis, P., Rankin, B.M., Wahl, A.F., Aruffo, A., Hollenbaugh, D., 1995. Stimulation of CD40 with purified soluble gp39 induces pro-inflammatory responses in human monocytes. J. Immunol. 155, 4917-4925.

Kojima, K., Berger, Th., Lassmann, H., Hinze-Selch, D., Zhan, Y., Lu, H., Lassmann, H., Wekerle, H., 1993. Experimental autoimmune panencephalitis and uveoretinitis transferred to the Lewis rat by T-lymphocytes specific for the $\mathrm{S}-100 \beta$ molecule, a calcium-binding protein of astroglia. J. Exp. Med. 180, 817-829.

Koshy, M., Berger, D., Crow, M.K., 1996. Increased expression of CD40 ligand on systemic lupus erythematosus lymphocytes. J. Clin. Invest. 98, 826-837.

Kuchroo, V.K., Prabhu Das, M., Brown, J.A., Ranger, A.M., Zamvil, S.S., Sobel, R.A., Weiner, H.L., Nabavi, N., Glimcher, L.H., 1995. B7-1 and B7-2 costimulatory molecules activate differentially the Th1/Th2 developmental pathways: application to autoimmune disease therapy. Cell 80, 707-718.

Kwekkeboom, J., De Boer, M., Mevissen, M.L.C.M., Tager, J.M., De Groot, C., 1993. Signalling via CD40 plays an essential role in the activation of human B cells by murine EL4B5 cells. Immunol. 79, 439-445.

Laman, J.D., Claassen, E., Noelle, R.J., 1996. Functions of CD40 and its ligand, gp39. Crit. Rev. Immunol. 16, 59-108.

Laman, J.D., De Smet, B.J.L.G., Schoneveld, A., van Meurs, M., 1997. CD4-CD4L interactions in atherosclerosis. Immunol. Today 18, 272 277.

Lassmann, H. (in press) Multiple sclerosis pathology. In: McAlpine's Multiple Sclerosis, 3rd edn.

Lassmann, H., 1983. Comparative neuropathology of chronic experimental allergic encephalomyelitis and multiple sclerosis. Neurology series, Vol. 25. Springer, Berlin.

Linington, C., Lassmann, H., 1987. Antibody responses in chronic relapsing experimental allergic encephalomyelitis: correlation of serum demyelinating activity with the antibody titre to the myelin/oligodendrocyte glycoprotein (MOG). J. Neuroimmunol. 17, 61-69.

Linington, C., Engelhardt, B., Kapocs, G., Lassmann, H., 1992. Induction of persistently demyelinated lesions in the rat following the repeated adoptive transfer of encephalitogenic $\mathrm{T}$ cells and demyelinating antibody. J. Neuroimmunol. 40, 219-224.

Liles, W.C., Van Voorhis, W.C., 1995. Nomenclature and biologic 
significance of cytokines involved in inflammation and the host immune response. J. Inf. Dis. 172, 1573-1580.

Marburg, O., 1906. Die sogenannte "akute Multiple Sklerose". Jahrb. Psychiatrie 27, 211-312.

Massacesi, L., Genain, C.P., Lee-Parritz, D., Letvin, N.L., Canfield, D., Hauser, S.L., 1995. Active and passively induced experimental autoimmune encephalomyelitis in common marmosets: a new model for multiple sclerosis. Ann. Neurol. 37, 519-530.

McFarland, H.F., 1994. Significance of autoreactive T cells in diseases such as multiple sclerosis using an innovative primate model. J. Clin. Invest. 94, 921-922.

McFarland, H.F., 1995. The multiple sclerosis lesion. Ann. Neurol. 37, 419-421.

McFarland, H.F., 1996. Complexities in the treatment of autoimmune disease. Sci. 247, 2037-2038.

Miller, S.D., Vanderlugt, C.L., Lenschow, D.J., Pope, J.G., Karandikar, N.J., Dal Canto, M.D., Bluestone, J.A., 1995. Blockade of CD28/B71 interaction prevents epitope spreading and clinical relapses of murine EAE. Immunity, 739-745.

Mohan, C., Shi, Y., Laman, J.D., Datta, S.K., 1995. Interaction between CD40 and its ligand gp39 in the development of murine lupus nephritis. J. Immunol. 154, 1470-1480.

Olsson, T., 1995. Critical influences of the cytokine orchestration on the outcome of myelin antigen-specific T-cell autoimmunity in experimental autoimmune encephalomyelitis and multiple sclerosis. Immunol. Rev. 144, 245-268.

Peng, X., Kasran, A., Warmerdam, P.A.M., De Boer, M., Ceuppens, J.L., 1996. Accessory signaling by CD40 for T cell activation: induction of Th1 and Th2 cytokines and synergy with interleukin-12 for interferon- $\gamma$ production. Eur. J. Immmunol. 26, 1621-1627.

Perrin, P.J., Scott, D., Quigley, L., Albert, P.S., Feder, O., Gray, G.S., Abe, R., June, C.H., Racke, M.K., 1995. Role of B7:CD28/CTLA-4 in the induction of chronic relapsing experimental allergic encephalomyelitis. J. Immunol. 154, 1481-1490.

Racke, M.K., Scott, D.E., Quigley, L., Gray, G.S., Abe, R., June, C.H., Perrin, P.J., 1995. Distinct roles for B7-1 (CD80) and B7-2 (CD86) in the initiation of experimental allergic encephalomyelitis. J. Clin. Invest. 96, 2195-2203.

Roy, M., Aruffo, A., Ledbetter, J.A., Linsley, P., Kehry, M., Noelle, R.J., 1995. Studies on the interdependence of gp39 and B7 expression and function during antigen-specific immune responses. Eur. J. Immunol. 25, 596-603.

Shu, U., Kiniwa, M., Wu, C.Y., Maliszewski, C., Vezzio, N., Hakimi, J., Gately, M., Delespesse, G., 1995. Activated T cells induce interleukin-12 production by monocytes via CD40-CD40 ligand interaction. Eur. J. Immunol. 25, 1125-1128.

Soong, L., Xu, J.-C., Grewal, I.S., Kima, P., Sun, J., Longley, B.J., Ruddle, N.H., McMahon-Pratt, D., Flavell, R.A., 1996. Disruption of CD40-CD40 ligand interactions results in an enhanced susceptibility to Leishmania amazonensis infection. Immunity 4, 263-273.
Stout, R.D., Suttles, J., Xu, J., Grewal, I.S., Flavell, R.A., 1996. Impaired $\mathrm{T}$ cell macrophage activation in CD40 ligand-deficient mice. J. Immunol. 156, 8-11.

Stuber, E., Strober, W., Neurath, M., 1996. Blocking the CD40L-CD40 interaction in vivo specifically prevents the priming of $\mathrm{T}$ helper 1 cells through the inhibition of interleukin 12 secretion. J. Exp. Med. 183, 693-698.

Swanborg, R.H., 1995. Animal models of human disease: Experimental autoimmune encephalomyelitis in rodents as a model for human demyelinating disease. Clin. Immunol. Immunopathol. 77, 4-13.

Tian, L., Noelle, R.J., Lawrence, D.A., 1995. Activated T cells enhance nitric oxide production by murine splenic macrophages through gp39 and LFA-1. Eur. J. Immunol. 25, 306-309.

Van Essen, D., Kikutani, H., Gray, D., 1995. CD40 ligand-transduced co-stimulation of $\mathrm{T}$ cells in the development of helper function. Nature 378, 620-623.

Van Kooten, C., Banchereau, J., 1996. CD40-CD40 ligand, a multifunctional receptor-ligand pair. Adv. Immunol. 61, 1-77.

Van Noort, J.M., El Ouagmiri, M., Boon, J., Van Sechel, A.C., 1994. Fractionation of central nervous system myelin proteins by reversed phase high-performance liquid chromatography. J. Chromatogr. 653, $155-161$.

Van Noort, J.M., Van Sechel, A.C., Bajramovic, J.A., El Ouagmiri, M., Polman, C.H., Lassmann, H., Ravid, R., 1995. The small heat-shock protein alphaB-crystallin as candidate autoantigen in multiple sclerosis. Nature 375, 798-801.

Wagner, D.H., Stout, R.D., Suttles, J., 1994. Role of the CD40-CD40 ligand interaction in $\mathrm{CD} 4+\mathrm{T}$ cell contact-dependent activation of monocyte interleukin-1 synthesis. Eur. J. Immunol. 24, 3148-3154.

Wiley, J.A., Harmsen, A.G., 1995. CD40 ligand is required for resolution of Pneumocystis carinii pneumonia in mice. J. Immunol. 155, 35253529.

Windhagen, A., Newcombe, J., Dangond, F., Strand, C., Woodroofe, M.N., Cuzner, M.L., Hafler, D.A., 1995. Expression of costimulatory molecules B7-1 (CD80), B7-1 (CD86) and interleukin 12 cytokine in multiple sclerosis lesions. J. Exp. Med. 182, 1985-1996.

Woodroofe, M.N., 1995. Cytokine production in the central nervous system. Neurol. 45, 6-10, Suppl. 6.

Woodroofe, M.N., Cuzner, M.L., 1993. Cytokine mRNA expression in inflammatory multiple sclerosis lesions: detection by nonradioactive in situ hybridization. Cytokine 5, 583-588.

Wucherpfennig, K.W., Strominger, J.L., 1995. Molecular mimicry in T cell-mediated autoimmunity: viral peptides activate human $\mathrm{T}$ cell clones specific for myelin basic protein. Cell 80, 695-705.

Yellin, M.J., Sippel, K., Inghirami, G., Covey, L.R., Lee, J.J., Sinning, J., Clark, E.A., Chess, L., Lederman, S., 1994. CD40 molecules induce down-modulation and endocytosis of $\mathrm{T}$ cell surface $\mathrm{T}$ cell-B cell activating molecule/CD40-L Potential role in regulating helper effector function. J. Immunol. 152, 598-608. 